\title{
Knowledge, Attitude, and Practices Toward COVID-19 in Primary Healthcare Providers: A Cross-Sectional Study from Three Tertiary Care Hospitals of Peshawar, Pakistan
}

\author{
Iltaf Hussain ${ }^{1} \cdot$ Abdul Majeed $^{1} \cdot$ Imran Imran $^{2} \cdot$ Muhib Ullah $^{3} \cdot$ Furqan K. Hashmi ${ }^{4} \cdot$ Hamid Saeed $^{4}$. \\ Muhammad O. Chaudhry ${ }^{5}$. Muhammad F. Rasool ${ }^{1}$ (1)
}

Published online: 6 July 2020

๑) Springer Science+Business Media, LLC, part of Springer Nature 2020

\begin{abstract}
An online cross-sectional study was carried out to evaluate the knowledge, attitude, and practice about coronavirus disease 2019 (COVID-19) among primary health care providers (PHPs) at three tertiary care hospital, Peshawar, Pakistan. Data was collected via email and online social media platforms. Statistical package for social science (SPSS) version 25.0 was used for data analysis. Among the total participants $(n=114), 74(66.7 \%)$ were male and $37(33.3 \%)$ were female. The mean scores for knowledge, attitude and practice were $12.7 \pm 0.89,8.9 \pm 4.1$ and $7.3 \pm 1.2$, respectively. Most of the participants knew the term COVID-19 and its mode of transmission (90\%), signs and symptoms (84\%) and risk factors (72\%) associated with it. Most of the participants agreed that COVID-19 can be transmitted through coughing and sneezing $(74.3 \%)$ and $84.6 \%$ were in favor that COVID-19 can be prevented by adopting preventive measures. Around $68.8 \%$ of the participants disagreed with the use of antibiotics in the prevention of COVID-19. Ninety percent of the respondents were avoiding close contact with the people having cough and flu-like symptoms. Most PHPs had good knowledge, positive attitude and reasonable practices regarding COVID-19. Moreover, focused training programs for PHPs at the Government level can further improve their understanding of risks and preventive strategies related to COVID-19, which will help them to provide appropriate care to their patients as well as to protect themselves from this infection.
\end{abstract}

Keywords COVID-19 $\cdot$ Knowledge $\cdot$ Attitude $\cdot$ Practices $\cdot$ Primary healthcare providers $\cdot$ Peshawar

\section{Introduction}

Coronavirus disease 2019 (COVID-19) is the emerging respiratory disease that is caused by a novel coronavirus. It was first reported in Wuhan, China in December 2019 [1, 2]. The main clinical symptoms of this highly infectious disease

Muhammad F. Rasool

fawadrasool@bzu.edu.pk

1 Department of Pharmacy Practice, Faculty of Pharmacy, Bahauddin Zakariya University, Multan 60800, Pakistan

2 Department of Pharmacology, Faculty of Pharmacy, Bahauddin Zakariya University, Multan 60800, Pakistan

3 Hayatabad Medical Complex, Peshawar, Pakistan

4 University College of Pharmacy, University of the Punjab, Allama Iqbal Campus, Lahore 54000, Pakistan

5 School of Economics, Bahauddin Zakariya University, Multan 60800, Pakistan include fever, dry cough, fatigue, myalgia and shortness of breath. The advanced stage of COVID-19 is characterized by respiratory distress syndrome, septic shock, bleeding and coagulation dysfunction $[3,4]$.

Since, December 2019, the COVID-19 has spread from Wuhan city to other cities of China and ultimately around the whole world [1,5]. The World Health Organization (WHO) has declared the COVID-19 outbreak a public health emergency of international concern on 30th January 2020 and a pandemic on 11th March 2020. To date (9th April, 2020), there are 1.4 million laboratory-confirmed cases of COVID-19 in the world and 85,582 deaths have been associated with it [6].

It has been reported that around 209 countries are affected due to COVID-19 in the world [5]. Pakistan is also been hit by this infection and the number of confirmed COVID-19 cases are increasing by every passing day. According to the Ministry of National Health Services, Regulation and Coordination (MoNHSRC) the confirmed cases of COVID-19 till 
6th April 2020 were 4601 and the associated deaths were 66. The laboratory-confirmed cases of COVID-19 in Khyber Pakhtunkhwa (KPK) province were 620 and 22 deaths have been reported with it. In comparison with other provinces of Pakistan (death rates: Sindh 1.86\%, Punjab 0.7\%, Balochistan $0.4 \%$ ), KPK ranks at first position regarding the associated death with (death rate of 3.4\%) COVID-19 [7]. The Government of Pakistan has taken unprecedented measures to control the COVID-19 spread in Pakistan. These measures include, suspension of public transportation services, the closing of schools and universities and implementation of general lockdown in the country along with special measures to isolate the infected and suspected cases [7, 8].
The battle against COVID-19 is still ongoing in Pakistan. In order to achieve success against the spread of COVID-19, the adherence to the control measures by the Primary Health Providers (PHPs) and the public are very important. The knowledge, attitude and practices of the PHPs towards COVID-19 infection will play a vital role in controlling this pandemic $[1,9]$.

\section{Aims}

To facilitate the management and control of COVID-19 in Pakistan, there is an urgent need to understand the awareness of PHPs regarding COVID-19. In this study, we have

Table 1 Questionnaire to evaluate the level of knowledge, attitudes and practices about COVID-19 among PHPs of three tertiary care hospitals in Peshawar, Pakistan

K1. Have you ever heard about the novel coronavirus and the related terms COVID-19 or 2019-nCoV

K2. COVID-19 disease is a viral infection

K3. Fever, sore throat, cough and shortness of breath are possible K4 symptoms of COVID-19 infection

K4. The novel coronavirus is a similar virus as SARS-CoV and MERS-CoV

K5. The novel coronavirus is a similar virus as SARS-CoV and MERS-CoV

K6. Is the COVID-19 infection the same illness as flu or cold?

K7. Is there any laboratory test to confirm the presence of COVID-19 infection?

K8. The incubation period of COVID-19 infection is 1-2 weeks?

K9. Can COVID-19 infection be caught from a person who presents no symptoms and has recently visited the affected area?

K10. People with a compromised immune system and old age people are at more risk of developing the infection?

K11. Patients with comorbidities are at more risk of developing the infection

K12. Health care workers and hospitalized patients who are near to infected patients are at more risk of developing the infection

K13. People in crowded places are at increased risk of getting affected by the disease

K14. Patients of COVID-19 infection should be immediately isolated to avoid the transfer of infection to other people

A1. The disease can be transmitted by coughing and sneezing

A2. Transmission of COVID-19 infection can be prevented through wearing masks

A3. Transmission of COVID-19 infection can be prevented through washing hands and face regularly with antiseptics and sanitizers

A4. Transmission of COVID-19 infection can be prevented through the isolation of COVID-19 infected patients

A5. Transmission of COVID-19 infection can be prevented by taking antibiotics

A6. Restricting the travel of COVID-19 infected people to other areas of the world and of people in other areas to affected areas can be beneficial to prevent the spread of the infection

A7. Avoiding touching nose, mouth and eyes can reduce the risk of infection

A8. Avoiding touching the surface of doors, furniture or other things can be helpful in preventing the disease

A9. If a vaccine is developed against the novel coronavirus, it can significantly reduce the epidemic spread

A10. The available information about COVID-19 disease is sufficient in Pakistani society

A11. The government in our country has all the necessary healthcare facilities and are able to control the epidemic situation

P1. I eat thoroughly cooked food especially meat products

P2. I am keeping myself warm and hydrated

P3. I am using soap or sanitizer to wash their hands and face

P4. I am avoiding close contact with people having cough and flu-like symptoms

P5. During interaction with the Covid-19 patient, I wear the necessary personal protective equipment such as masks, gloves and gown etc

P6. I perform hand hygiene before and after touching the Covid-19 patients or before and after performing an aseptic procedure

P7. I perform hand hygiene after touching the patient's surroundings like beds, tables, doors etc

P8. I avoid unnecessary close contact and practice social distancing and keep at least 1-m distance from patients and other healthcare workers

P9. The government in our country has all the necessary healthcare facilities and are able to control the epidemic situation
Yes no I don't know

Yes no I don't know

Yes no I don't know

Yes no I don't know

Yes no I don't know

Yes no I don't know

Yes no I don't know

Yes no I don't know

Yes no I don't know

Yes no I don't know

Yes no I don't know

Yes no I don't know

Yes no I don't know

Yes no I don't know

Agree Neutral Disagree

Agree Neutral Disagree

Agree Neutral Disagree

Agree Neutral Disagree

Agree Neutral Disagree

Agree Neutral Disagree

Agree Neutral Disagree

Agree Neutral Disagree

Agree Neutral Disagree

Agree Neutral Disagree

Agree Neutral Disagree

Often Sometime Never

Often Sometime Never

Often Sometime Never

Often Sometime Never

Often Sometime Never

Often Sometime Never

Often Sometime Never

Often Sometime Never

Often Sometime Never 
investigated the knowledge, attitudes, and practices of PHPs towards COVID-19 in three tertiary care hospitals of Peshawar, KPK, Pakistan.

\section{Methods}

\section{Study Design and Settings}

A cross-sectional survey was conducted from March 15 to April 4, 2020 in three tertiary care hospitals, named as Hayatabad Medical Complex (HMC), Khyber Teaching Hospital (KTH) and Lady Reading Hospital (LRH), located in Peshawar, Pakistan.

\section{Ethical Approval and Consent to Participate}

This research involved online data collection from the participants. Every participant gave an online informed consent before filling the study questionnaire. The study was approved by the Ethical Committee of the Department of Pharmacy Practice, Bahauddin Zakariya University (BZU), Multan (reference number Acad/21/20/11).

\section{Measuring Instrument}

A self-administered questionnaire was developed and validated in a pilot study of 22 participants. The Cronbach's alpha coefficient for the developed questionnaire was 0.76 , which indicates acceptable internal consistency. This questionnaire consisted of four parts as shown in Table 1. The first part was regarding demographics including age, gender, occupation, residence, and workplace. The second part comprised of 14 questions regarding COVID-19 knowledge (K1-K14, Table 1). Each question had three possible answers, yes/no and "I don't know". The total knowledge score ranged from 0 to 14 . A mean knowledge score $\geq 10$ represent good knowledge. A correct response was assigned 1 point and incorrect/ I don't know was assigned 0 points. The third part comprised of 11 questions regarding attitude toward COVID-19 (A1-A11, Table 1). These questions were answered on 3-point Likert Scale (disagree, neutral and agree) and a mean score equal or less than 11 was associated with a positive attitude. The final part was regarding prevention practices associated with COVID-19 and were answered on some time, often and never basis (P1-P9, Table 1). A mean score equal to or less than 8 was an indicator of good preventive practices and a score greater than 8 was associated with poor preventive practices.

\section{Data Collection}

The questionnaire was developed using Google Docs (Google LLC. USA) and its online link was shared with the PHPs through email and via online social media. The questionnaire contained a brief introduction to the background, objective, procedures, voluntary nature of participation, declarations of anonymity and confidentiality, and the notes for filling in the questionnaire.

\section{Statistical Analysis}

The statistical package for social science (SPSS) version 25.0 (IBM Corp. Armonk, NY) was used to analyze the data. Descriptive statistics including frequency, percentage, mean, and standard deviation were used to describe sample characteristics, level of knowledge, attitudes, and practices. Chi-square test $\left(\chi^{2}\right)$ was used for categorical variables and for scale variables, student t-test and Mann-Whitney U test were used.

Table 2 Demographics characteristics of the participants $(n=114)$

\begin{tabular}{|c|c|c|}
\hline & Mean & Standard Deviation \\
\hline \multirow[t]{2}{*}{ Age } & 26 & 2 \\
\hline & Frequency (n) & Percentage (\%) \\
\hline \multicolumn{3}{|l|}{ Gender } \\
\hline Male & 74 & $66.7 \%$ \\
\hline Female & 37 & $33.3 \%$ \\
\hline \multicolumn{3}{|l|}{ Marital status } \\
\hline Married & 41 & 36.6 \\
\hline Unmarried & 71 & $63.4 \%$ \\
\hline \multicolumn{3}{|c|}{ Education level } \\
\hline Bachelor & 54 & $48.2 \%$ \\
\hline Master & 38 & $33.9 \%$ \\
\hline Doctorate & 20 & $17.9 \%$ \\
\hline \multicolumn{3}{|l|}{ Profession } \\
\hline Pharmacist & 44 & $39.3 \%$ \\
\hline Physician & 46 & $41.1 \%$ \\
\hline Nurse & 22 & $19.6 \%$ \\
\hline \multicolumn{3}{|l|}{ Hospital } \\
\hline HMC & 65 & $57.5 \%$ \\
\hline KTH & 22 & $19.5 \%$ \\
\hline LRH & 26 & $23.0 \%$ \\
\hline \multicolumn{3}{|l|}{ Residence } \\
\hline Urban & 78 & 69.9 \\
\hline Rural & 34 & 30.4 \\
\hline
\end{tabular}




\section{Results}

A total of 114 participants completed the survey, amongst which $74(66.7 \%$ ) were male and $37(33.3 \%)$ were female. The mean age ( \pm standard deviation) of the participants was $26.0 \pm 2.0$ (range: $22-33$ ). Ninety-two $(82.1 \%$ ) respondents were having a bachelor or master's degree. Most of the participants were un-married $71(63.4 \%)$ and most of the respondents were from HMC 65(57.5\%). Other demographics characteristics are shown in Table 2.

The participants of the survey had a good overall knowledge of COVID-19. The mean COVID-19 knowledge score was $12.7 \pm 0.89$ (range: $0-14$ ) showing that $90.7 \%$ of participants had knowledge about the COVID-19. Knowledge score was significantly different across the professions $(\mathrm{p}=0.003)$, and hospitals $(\mathrm{p}=0.007)$. The knowledge scores of PHPs regarding COVID-19 can be seen in Table 3. Almost $90 \%$ of the participants knew the term COVID-19 and its mode of transmission. Most of the participants knew the signs and symptoms (84\%) and risk factors (72\%) associated with COVID-19. The results related to the participant's knowledge can be seen in Table 4.

The majority of the respondents showed a positive attitude towards COVID-19 infection. Their mean score was
$8.9 \pm 4.1$, suggesting that $90 \%$ of the respondents had a positive attitude toward the COVID-19 infection as shown in Table 3. Most of the participant agreed that COVID-19 can be transmitted through coughing and sneezing (74.3\%) and can be prevented by, wearing a mask $(88.3 \%)$, washing hands $(81.7 \%)$, isolating the infected patient (95\%), restricting travel to infected areas $(85.6 \%)$ and avoiding touching nose, eyes, and mouth $(97.3 \%)$. Concerning the use of the antibiotics in the prevention of COVID-19, around $2 \%$ of respondents were in its favor and $68.8 \%$ were against the statement as shown in Table 5. The attitude toward COVID19 significantly differed with age $(\mathrm{p}<0.0001)$, marital status $(\mathrm{p}=0.0001)$, profession $(\mathrm{p}<0.0001)$, hospital $(\mathrm{p}=0.02)$ and residential place $(\mathrm{p}=0.001)$ (Table 3$)$.

The mean practice score of PHPs toward COVID-19 was $7.3 \pm 1.2$, which suggested that overall COVID-19 preventive practices were good. Most of the respondents were, eating thoroughly cooked food, keeping themselves warm and hydrated, avoiding close contact with the people having cough and flu-like symptoms and wearing personal protective equipment during interaction with COVID-19 patients. Most of the participants were taking care of proper hand hygiene before and after interaction with COVID-19 patients. Almost $100 \%$ practiced social distancing of one
Table 3 Knowledge, Attitude and Practices scores of PHPs about COVID-19

\begin{tabular}{|c|c|c|c|c|c|c|}
\hline \multirow[t]{2}{*}{ Mean \pm SD } & \multicolumn{2}{|c|}{ Knowledge score } & \multicolumn{2}{|c|}{ Attitude score } & \multicolumn{2}{|l|}{ Practice score } \\
\hline & Mean \pm SD & P-value & Mean \pm SD & P-value & Mean \pm SD & P-value \\
\hline \multicolumn{7}{|l|}{ Age (years) } \\
\hline $26.4 \pm 2.01$ & $12.75 \pm 0.89$ & $<0.0001$ & $8.9 \pm 4.32$ & $<0.0001$ & $12.75 \pm 0.89$ & $<0.0001$ \\
\hline \multicolumn{7}{|l|}{ Gender } \\
\hline Male & $12.73 \pm 0.91$ & 0.5 & $8.81 \pm 4.17$ & 0.2 & $11.89 \pm 2.45$ & 0.31 \\
\hline Female & $12.78 \pm 0.89$ & & $9.27 \pm 4.45$ & & $11.38 \pm 2.40$ & \\
\hline \multicolumn{7}{|l|}{ Marital status } \\
\hline Married & $12.65 \pm 1.10$ & 0.5 & $8.03 \pm 4.30$ & 0.002 & $11.18 \pm 2.56$ & 0.002 \\
\hline Unmarried & $12.93 \pm 0.26$ & & $10.68 \pm 3.57$ & & $12.71 \pm 1.86$ & \\
\hline \multicolumn{7}{|c|}{ Education level } \\
\hline Bachelor & $12.67 \pm 0.95$ & 0.6 & $10.91 \pm 3.03$ & 0.0001 & $11.17 \pm 2.63$ & $<0.0001$ \\
\hline Master & $12.82 \pm 0.98$ & & $9.58 \pm 3.37$ & & $12.24 \pm 1.95$ & \\
\hline Doctorate & $12.85 \pm 0.49$ & & $2.75 \pm 2.12$ & & $12.35 \pm 2.46$ & \\
\hline \multicolumn{7}{|l|}{ Profession } \\
\hline Pharmacist & $12.93 \pm 0.25$ & 0.003 & $9.14 \pm 3.85$ & $<0.0001$ & $11.07 \pm 2.75$ & $<0.0001$ \\
\hline Physician & $12.85 \pm 0.89$ & & $10.82 \pm 3.37$ & & $12.26 \pm 2.00$ & \\
\hline Nurse & $12.18 \pm 1.40$ & & $4.91 \pm 3.88$ & & $12.00 \pm 2.37$ & \\
\hline \multicolumn{7}{|l|}{ Hospital } \\
\hline HMC & $12.71 \pm 0.78$ & 0.007 & $8.44 \pm 4.49$ & 0.02 & $12.11 \pm 1.99$ & $<0.0001$ \\
\hline KTH & $13.00 \pm 0.0$ & & $11.09 \pm .30$ & & $11.05 \pm 3.42$ & \\
\hline LRH & $12.88 \pm 1.31$ & & $11.89 \pm .93$ & & $11.54 \pm 2.35$ & \\
\hline \multicolumn{7}{|l|}{ Residence } \\
\hline Urban & $12.73 \pm 0.83$ & 0.3 & $9.84 \pm 3.91$ & 0.001 & $11.15 \pm 2.32$ & 0.02 \\
\hline Rural & $12.79 \pm 1.04$ & & $7.03 \pm 4.34$ & & $13.09 \pm 2.17$ & \\
\hline
\end{tabular}


Table 4 Knowledge about COVID-19

Frequency (n) Percentage (\%)

Have you heard about the novel coronavirus and the related terms COVID-19 or 2019-nCoV

Yes

No

106

94.5

Don't know

0

COVID-19 disease is a viral infection

Yes

101

No

Don't know

COVID-19 can be transmitted through close contact with infected people and infected animals

Yes

No

Don't know

Fever, sore throat, cough and shortness of breath are possible symptoms of COVID-19 infection Yes

No

Don't know

The novel coronavirus is a similar virus as SARS-CoV and MERS-CoV

Yes

No

Don't know

Is the COVID-19 infection the same illness as flu or cold?

Yes

No

Don't know

Is there any laboratory test to confirm the presence of COVID-19 infection?

Yes

No

Don't know

The incubation period of COVID-19 infection is 1-2 weeks?

Yes

$\begin{array}{rl}106 & 94.5 \\ 0 & 0 \\ 6 & 5.4\end{array}$

Don't know

Can COVID-19 infection be caught from a person who presents no symptoms and has recently visited the affected area?

Yes

No

Don't know

People with a compromised immune system and old age people are at more risk of developing the infection?

Yes

No

Don't know

Patients with comorbidities are at more risk of developing the infection

Yes

No

Don't know

Health care workers and hospitalized patients who are near to infected patients are at more risk of developing the infection

Yes

No

Don't know

People in crowded places are at increased risk of getting affected by the disease

Yes
96

6

96 
Table 4 (continued)

\begin{tabular}{|c|c|c|}
\hline & Frequency (n) & Percentage $(\%)$ \\
\hline No & 10 & 8.9 \\
\hline Don’t know & 6 & 5.4 \\
\hline \multicolumn{3}{|c|}{ Patients of COVID-19 infection should be immediately isolated to avoid the transfer of infection to other people } \\
\hline Yes & 104 & 92.9 \\
\hline No & 5 & 4.5 \\
\hline Don't know & 3 & 2.7 \\
\hline
\end{tabular}

meter from patients and other healthcare workers (Table 6). There was a significant difference across the age $(p<0.0001)$ educational level $(p=0.001)$, hospital $(p=0.04)$ and residence $(\mathrm{p}=0.02)$ of the participants as shown in Table 3 .

\section{Discussion}

To our knowledge, this is the first study in Pakistan that has assessed the KAP of PHPs toward the COVID-19 infection. The participants of this study had good overall knowledge about COVID-, as we found an overall correct response rate of $90.7 \%$ on the knowledge questionnaire. The knowledge score was significantly different across the professions $(p=0.003)$ and the hospitals $(p=0.007)$. Most of the respondents showed an optimistic attitude toward COVID19. The mean attitude score suggested that $80 \%$ of the respondents had a positive attitude toward the COVID-19 infection. The attitude toward COVID-19 significantly differed across the age $(\mathrm{p}<0.0001)$, profession $(\mathrm{p}<0.0001)$ and hospital $(\mathrm{p}=0.02)$. Despite this, the PHPs adopted good preventive practices regarding COVID-19. The mean practice score of $7.3 \pm 1.2$, suggested that the preventive practices regarding COVID-19 among the PHPs were acceptable.

Knowledge greatly reflects the practice of individuals as it provides a base for good practice [10]. The knowledge of PHPs regarding COVID-19 is of paramount importance as they are on the frontline in dealing with the COVID-19 outbreak. The Physicians, Pharmacists, and Nurses are the professionals who are in direct contact with the COVID19 infected patients and they must be fully aware of the associated risks with this infection. In the presented study the correct knowledge response rate was $90 \%$, this finding was consistent with studies conducted in China (90\%) [1] and Kenya (88\%) [9], but was higher than that of Jordon (40\%) [11]. One study from China reported that $89.5 \%$ of the participants knew COVID-19 which was in line with our study [12]. The knowledge of the Iranian general population about COVID-19 was $87 \%$ which is consistent with our study [13]. Another study from China reported that $88 \%$ of the healthcare workers knew COVID-19 (knowledge score: $8.17 \pm 1.30$ ), this finding was in line with our study [14].
The present study demonstrated that most of the respondents showed a positive attitude toward COVID-19. Almost 80-90\% of the respondents agreed that infection can be prevented by wearing masks, washing hands, using sanitizer and soap, restricting travel to infected areas, isolation of infected patients and avoiding touching nose, eyes, and mouth, which was consistent with studies reported from China (94\%) [1] and Iran (90\%) [13]. Another study from China stated that $93.3 \%$ of the participant agreed with the statements that COVID-19 transmission can be prevented by washing hands with soap frequently, isolation of COVID-19 positive patients and acceptance of isolation after getting COVID-19 (attitude score: $1.86 \pm 0.43$, range: $1-4$ ) which was in line with our findings [14].

The adaption of preventive practices is the only solution to defeat the COVID-19, as to date, there is no specific treatment and prevention for the novel coronavirus [15]. In the present study preventive practice adopted by the PHPs were appreciable. The majority of respondents often practiced thoroughly cooked food (92\%), keeping themselves warm and hydrated (69.6\%), avoiding close contact with the people having cough and flu like symptoms (76\%) and wearing personal protective equipment during interaction with COVID-19 patients $(88.4 \%)$. Most of the participants had performed hand hygiene before and after interaction with COVID-19 patients (99.1\%). Almost $100 \%$ practiced social distance of one meter from patients and other healthcare workers. This figure was consistent with the reported studies from China, where 96\% of the respondents were practiced preventive practices by avoiding crowded places and wearing masks [1] and Jordon, where $87.5 \%$ of the participants adopted preventive practice by washing hands with alcohol or soap, wearing personal protective equipment (PPE) and putting a mask on confirmed or suspected patients [11]. Another study from Iran reported that $89 \%$ of the participants practiced preventive measures regarding COVID-19 (mean \pm SD: $32.1 \pm 2.9$, range: $12-36$ ) these numbers are consistent with our study [13]. The good PHPs practices seen in this study may be attributed to the various directives issued by the Government Agencies and by the awareness campaigns ran on the social and electronic media. 
Table 5 Attitude toward COVID-19

Frequency (n) Percentage (\%)

The disease can be transmitted by coughing and sneezing

$\begin{array}{lrr}\text { Agree } & 81 & 74.3 \\ \text { Neutral } & 27 & 24.8 \\ \text { Disagree } & 1 & 0.9 \\ \text { Transmission of COVID-19 infection can be prevented through wearing masks } & 98 & 88.3 \\ \text { Agree } & 11 & 9.9 \\ \text { Neutral } & 2 & 1.8 \\ \text { Disagree } & & 2\end{array}$

Transmission of COVID-19 infection can be prevented through washing hands and face regularly with antiseptics and sanitizers

$\begin{array}{lrr}\text { Agree } & 84 & 77.1 \\ \text { Neutral } & 20 & 18.3 \\ \text { Disagree } & 5 & 4.6\end{array}$

Transmission of COVID-19 infection can be prevented through the isolation of COVID-19 infected patients

$\begin{array}{lrr}\text { Agree } & 69 & 63.3 \\ \text { Neutral } & 29 & 26.6 \\ \text { Disagree } & 11 & 10.1 \\ \text { Transmission of COVID-19 infection can be prevented by taking antibiotics } & & \\ \text { Agree } & 2 & 1.8 \\ \text { Neutral } & 32 & 29.4 \\ \text { Disagree } & 75 & 68.8\end{array}$

Restricting the travel of COVID-19 infected people to other areas of the world and of people in other areas to affected areas can be beneficial to prevent the spread of the infection

$\begin{array}{lrr}\text { Agree } & 95 & 85.6 \\ \text { Neutral } & 14 & 12.6 \\ \text { Disagree } & 2 & 1.8\end{array}$

Avoiding touching nose, mouth and eyes can reduce the risk of infection

\begin{tabular}{ll} 
Agree & 108 \\
\hline
\end{tabular}

$\begin{array}{lrr}\text { Neutral } & 3 & 2.7\end{array}$

$\begin{array}{lrl}\text { Disagree } & 0 & 0.0\end{array}$

Avoiding touching the surface of doors, furniture or other things can be helpful in preventing the disease
Agree

$\begin{array}{lrl}\text { Neutral } & 28 & 25.7\end{array}$

\begin{tabular}{ll} 
Disagree & 2 \\
\hline
\end{tabular}

If a vaccine is developed against the novel coronavirus, it can significantly reduce the epidemic spread
Agree

$\begin{array}{lr}\text { Neutral } & 14 \quad 12.5\end{array}$

\begin{tabular}{lc} 
Disagree & 2 \\
\hline
\end{tabular}

The available information about COVID-19 disease is sufficient in Pakistani society

$\begin{array}{lll}\text { Agree } & 79 & 72.5\end{array}$

$\begin{array}{lrl}\text { Neutral } & 28 & 25.7\end{array}$

Disagree $\quad$\begin{tabular}{l}
28 \\
\hline
\end{tabular}

The government in our country has all the necessary healthcare facilities and are able to control the epidemic situation

$\begin{array}{lrr}\text { Agree } & 79 & 72.5 \\ \text { Neutral } & 28 & 25.7 \\ \text { Disagree } & 2 & 1.8\end{array}$

\section{Limitations of the Study}

In the present study, all the participants were from Peshawar, which is the provincial capital of KPK and they all had easy access to the internet but it is pertinent to mention that a considerable number of PHPs are working in basic health units (primary health care settings) of rural areas of Pakistan have very limited access to the internet and their knowledge, 
Table 6 Practice toward COVID-19

\begin{tabular}{|c|c|c|}
\hline & Frequency (n) & Percentage $(\%)$ \\
\hline \multicolumn{3}{|c|}{ I eat thoroughly cooked food especially meat products } \\
\hline Often & 103 & 92.0 \\
\hline Never & 0 & 0.0 \\
\hline Sometime & 9 & 8.0 \\
\hline \multicolumn{3}{|c|}{ I am keeping myself warm and hydrated } \\
\hline Often & 78 & 69.6 \\
\hline Never & 6 & 5.4 \\
\hline Sometime & 28 & 25.0 \\
\hline \multicolumn{3}{|c|}{ I am using soap or sanitizer to wash their hands and face } \\
\hline Often & 87 & 77.7 \\
\hline Never & 4 & 3.6 \\
\hline Sometime & 21 & 18.8 \\
\hline \multicolumn{3}{|c|}{ I am avoiding close contact with people having cough and flu-like symptoms } \\
\hline Often & 86 & 76.8 \\
\hline Never & 0 & 0.0 \\
\hline Sometime & 26 & 23.2 \\
\hline \multicolumn{3}{|c|}{ During interaction with the Covid-19 patient, I wear the necessary personal protective equipment such as masks, gloves and gown etc } \\
\hline Often & 99 & 88.4 \\
\hline Never & 0 & 0.0 \\
\hline Sometime & 13 & 11.6 \\
\hline \multicolumn{3}{|c|}{ I perform hand hygiene before and after touching the Covid-19 patients or before and after performing an aseptic procedure } \\
\hline Often & 94 & 83.9 \\
\hline Never & 0 & 0.0 \\
\hline Sometime & 18 & 16.1 \\
\hline \multicolumn{3}{|c|}{ I perform hand hygiene after touching the patient's surroundings like beds, tables, doors etc } \\
\hline Often & 111 & 99.1 \\
\hline Never & 0 & 0.0 \\
\hline Sometime & 1 & 0.9 \\
\hline \multicolumn{3}{|c|}{ I avoid unnecessary close contact and practice social distancing and keep at least 1-m distance from patients and other healthcare workers } \\
\hline Often & 110 & 99.1 \\
\hline Never & 0 & 0.0 \\
\hline Sometime & 1 & 0.9 \\
\hline
\end{tabular}

attitude, and practices (KAP's) regarding COVID-19 were not evaluated in this study. This may be a limitation of this study.

\section{Conclusion}

The findings from the current study suggested that PHPs have good knowledge, optimistic attitude and reasonable practices regarding COVID-19 infection. Moreover, focused training programs for PHPs can improve the understanding of risk and preventive strategies related to COVID-19 infection, which in turn can improve the confidence of PHPs to provide appropriate care to their patients as well as to protect themselves from this infection.
Hopefully, by designing effective COVID-19 prevention and management programs at Government level, countries like, Pakistan can manage the spread of COVID-19 infection.

Acknowledgements The authors wish to acknowledge the cooperation and support of all primary healthcare providers for the time and effort they devoted to the study.

Funding The presented work did not receive funding from any public or private funding agency.

\section{Compliance with Ethical Standards}

Conflict of interest The authors declare that they have no conflict of interest. 


\section{References}

1. Zhong, B.-L., Luo, W., Li, H.-M., Zhang, Q.-Q., Liu, X.-G., Li, W.-T., et al. (2020). Knowledge, attitudes, and practices towards COVID-19 among Chinese residents during the rapid rise period of the COVID-19 outbreak: A quick online cross-sectional survey. International Journal of Biological Sciences, 16(10), 1745.

2. Spagnuolo, G., De Vito, D., Rengo, S., \& Tatullo, M. (2020). COVID-19 outbreak: An overview on dentistry. Basel: Multidisciplinary Digital Publishing Institute.

3. Novel CPERE. (2020). The epidemiological characteristics of an outbreak of 2019 novel coronavirus diseases (COVID-19) in China. Zhonghua Liu Xing Bing Xue Za Zhi= Zhonghua Liuxingbingxue Zazhi, 41(2), 145.

4. Chen, N., Zhou, M., Dong, X., Qu, J., Gong, F., Han, Y., et al. (2020). Epidemiological and clinical characteristics of 99 cases of 2019 novel coronavirus pneumonia in Wuhan, China: A descriptive study. The Lancet, 395(10223), 507-513.

5. Munster, V. J., Koopmans, M., van Doremalen, N., van Riel, D., \& de Wit, E. (2020). A novel coronavirus emerging in China-Key questions for impact assessment. New England Journal of Medicine, 382(8), 692-694.

6. WHO. Coronavirus disease (COVID-2019) situation reports. Intenet source. 2020; Situation report - 80.

7. MoNHSRC. COVID-19 statistics. Intenet source. 2020

8. Dawn. Lockdown in pakistan to prevent COVID-19 spread. Internet source. 2020.

9. Abuya, T., Austrian, K., Isaac, A., Kangwana, B., Mbushi, F., Muluve, E., et al. (2020). COVID-19-related knowledge, attitudes, and practices in urban slums in Nairobi. Kenya: Study description.

10. Ajilore, K., Atakiti, I., \& Onyenankeya, K. (2017). College students' knowledge, attitudes and adherence to public service announcements on Ebola in Nigeria: Suggestions for improving future Ebola prevention education programmes. Health Education Journal, 76(6), 648-660.

11. Khader, Y., Al Nsour, M., Al-Batayneh, O. B., Saadeh, R., Bashier, H., Alfaqih, M., et al. (2020). Dentists' awareness, perception, and attitude regarding COVID-19 and infection control: A crosssectional study among Jordanian dentists. JMIR Public Health and Surveillance, 6, e18798.

12. Shi, Y., Wang, J., Yang, Y., Wang, Z., Wang, G., Hashimoto, K., et al. (2020). Knowledge and attitudes of medical staff in Chinese psychiatric hospitals regarding COVID-19. Brain, Behavior, \& Immunity-Health. https://doi.org/10.1016/j.bbih.2020.100064.

13. Erfani, A., Shahriarirad, R., Ranjbar, K., Mirahmadizadeh, A., Moghadami, M. This paper was submitted to the Bulletin of the World Health Organization and was posted to the COVID-19 open site, according to the protocol for public health emergencies for international concern as described in Vasee Moorthy et al.(https ://doi.org/10.2471/BLT.20.251561). The information herein is available for unrestricted use, distribution and reproduction in any medium, provided that the original work is properly cited as indicated by the Creative Commons.

14. Giao, H., Han, N. T. N., Van Khanh, T., Ngan, V. K., Van Tam, V., $\&$ Le An, P. (2020). Knowledge and attitude toward COVID-19 among healthcare workers at District 2 Hospital, Ho Chi Minh City. Asian Pacific Journal of Tropical Medicine, 13, 260.

15. Adhikari, S. P., Meng, S., Wu, Y.-J., Mao, Y.-P., Ye, R.-X., Wang, Q.-Z., et al. (2020). Epidemiology, causes, clinical manifestation and diagnosis, prevention and control of coronavirus disease (COVID-19) during the early outbreak period: A scoping review. Infectious diseases of poverty, 9(1), 1-12.

Publisher's Note Springer Nature remains neutral with regard to jurisdictional claims in published maps and institutional affiliations. 